\title{
Traumatic Anteromedial Radial Head Dislocation in an Adult: A Case of Brachialis Tendon Entrapment
}

\author{
Frrat Ozan ${ }^{1}$, Kürşat Tuğrul Okur ${ }^{1}$, Muhammed Melez ${ }^{1}$, Ömer Can Ünlü ${ }^{1}$, Kamil Yamak ${ }^{2}$ \\ 1. Orthopedics and Traumatology, Kayseri City Hospital, Kayseri, TUR 2. Orthopedics and Traumatology, İzmir \\ Bozyaka Training and Research Hospital, Izmir, TUR
}

Corresponding author: Frrat Ozan, triplon1@gmail.com

\section{Abstract}

Isolated traumatic anteromedial radial head dislocation is an uncommon injury in adults. The brachialis tendon interposition rarely interferes with the radial head reduction procedure. In the present paper, we report the case of an 18-year-old male who sustained an injury to his right elbow during a wrestling match and developed isolated anteromedial radial head dislocation. Open reduction had to be performed due to entrapment of the radial head at the brachialis tendon.

Categories: Orthopedics

Keywords: radial head dislocation, brachialis tendon interposition, irreducible joint dislocation, elbow, heterotopic ossification

\section{Introduction}

Traumatic radial head dislocation is usually observed with Monteggia type fractures, and children are more likely to suffer with isolated radial head dislocation than adults [1-3]. Isolated radial head dislocation without fracture and bowing in the ulnar bone is a rare occurrence in adults, with posterior dislocation being a more common manifestation [1-7].

Isolated traumatic anteromedial radial head dislocation in adults is rarely reported in the literature [4-5]. Only two cases of an irreducible anteromedial radial head dislocation due to soft tissue interposition have been reported in adult patients [4-5]. Moreover, inability to perform the radial head reduction due to brachialis tendon interposition is a very rare situation, with only one such case previously published in the literature $[1,4-7]$.

In this study, we report a rare case of isolated anteromedial radial head dislocation in an adult. Open reduction was performed due to entrapment of the radial head at the brachialis tendon.

Received 01/14/2019

Review began 01/16/2019 Review ended 01/17/2019 Published 01/21/2019

\section{() Copyright 2019}

Ozan et al. This is an open access article distributed under the terms of the Creative Commons Attribution License CC-BY 3.0., which permits unrestricted use, distribution, and reproduction in any medium, provided the original author and source are credited.

\section{Case Presentation}

An 18-year-old male patient presented to our emergency polyclinic with pain, swelling, deformity, and limited joint mobility in the right elbow. He had sustained an injury to his right elbow during a wrestling match. He had fallen backwards on an outstretched hand with his wrist in dorsiflexion and hyperpronation. The patient had a restricted active range of motion, especially the supination-pronation movements of the forearm. However, flexion-extension movements of the elbow joint were intact. Ecchymosis was present on the anteromedial aspect of the right elbow. Neurovascular status of the limb was normal.

X-ray images indicated isolated anteromedial radial head dislocation (Figure 1).

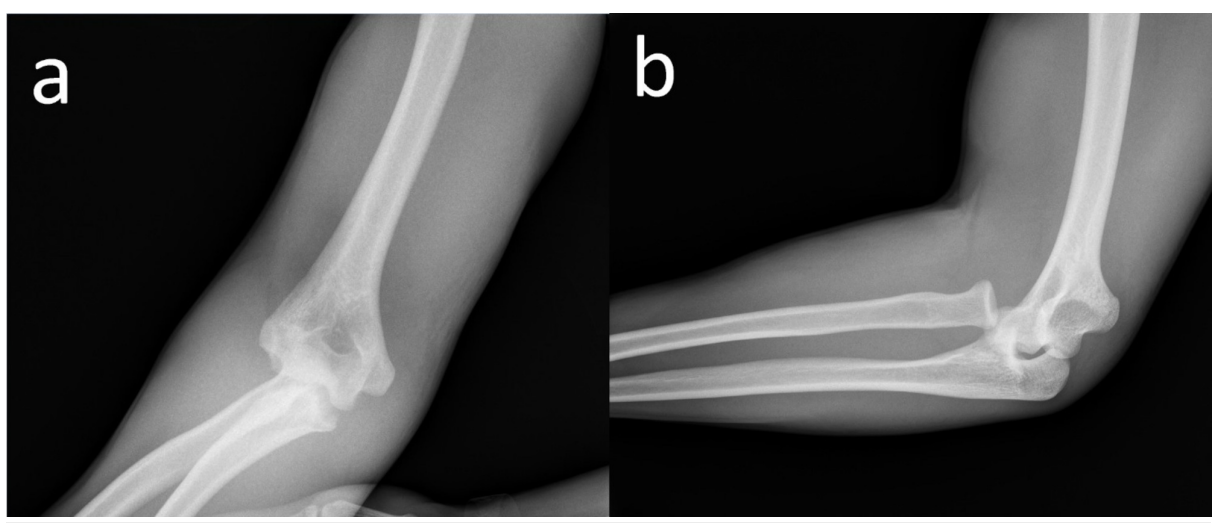




\section{Cureus}

FIGURE 1: Radiographic images of the patient immediately after injury.

Anteroposterior (a) and lateral (b) radiographic images of the patient indicating isolated anteromedial radial head dislocation of the right elbow.

A computed tomography (CT) scan of the elbow was performed (Figure 2).

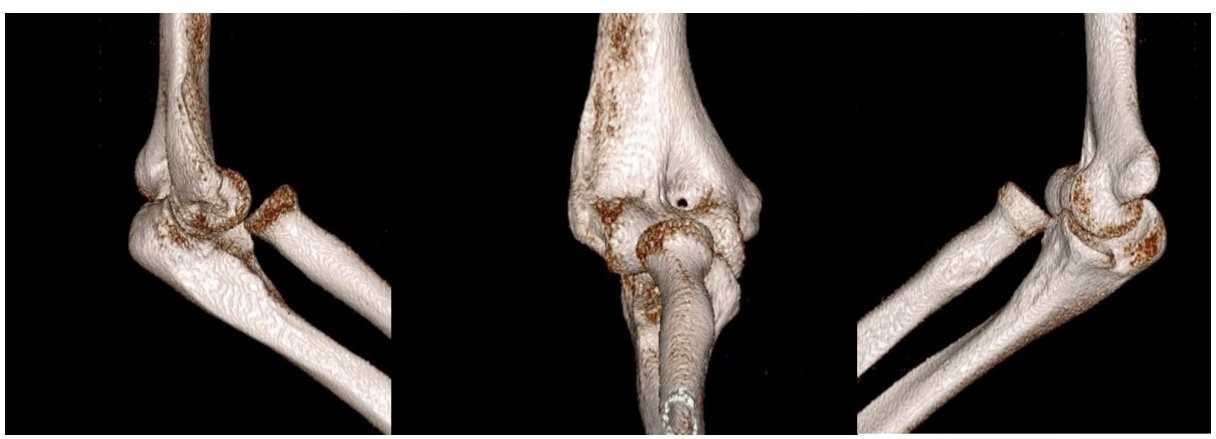

FIGURE 2: Computed tomography (CT) images of the elbow show isolated traumatic anteromedial radial head dislocation.

Closed reduction was attempted in the emergency room using various maneuvers; however, successful reduction could not be achieved.

Thus, an open reduction was considered. Boyd's approach was used to expose the radial head. A plane was made between the extensor carpi ulnaris and anconeus, and the radiocapitellar joint was exposed. We found that the brachialis tendon was wrapped around the radial neck and noted that the tendon pulled the dislocated radial head anteromedially. The brachialis tendon restricted radial head reduction. We also detected that the annular ligament was ruptured. The brachialis tendon was released from the radial head and the joint was reduced (Figure 3).

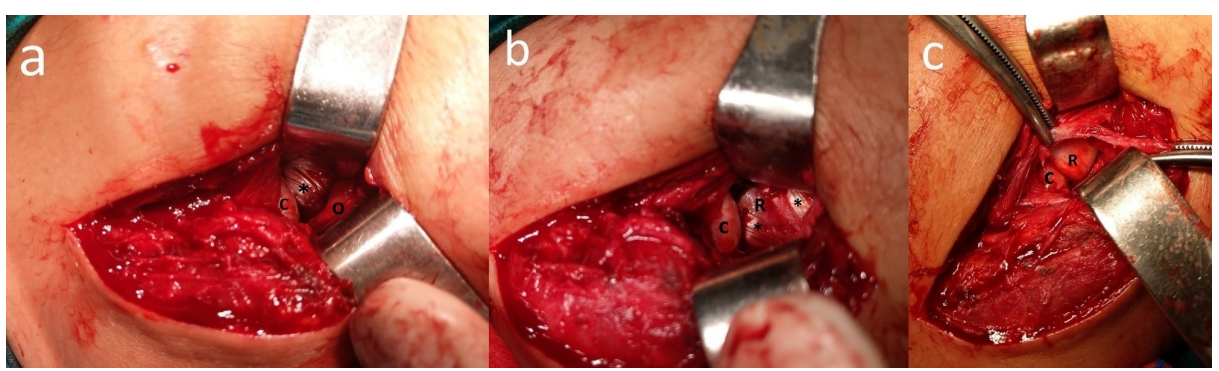

\section{FIGURE 3: Intraoperative view of the patient.}

(a, b) demonstrating the brachialis tendon wrapped around the radial head (C: Capitellum, R: Radial head, * Brachialis tendon, O: Olecranon); (c) Appearance of the radiocapitellar joint after reduction.

However, the reduction was unstable. Therefore, the annular ligament was repaired and a radioulnar Kirschner wire (K-wire) was used to maintain reduction of the proximal radioulnar joint (Figure 4). 


\section{Cureus}

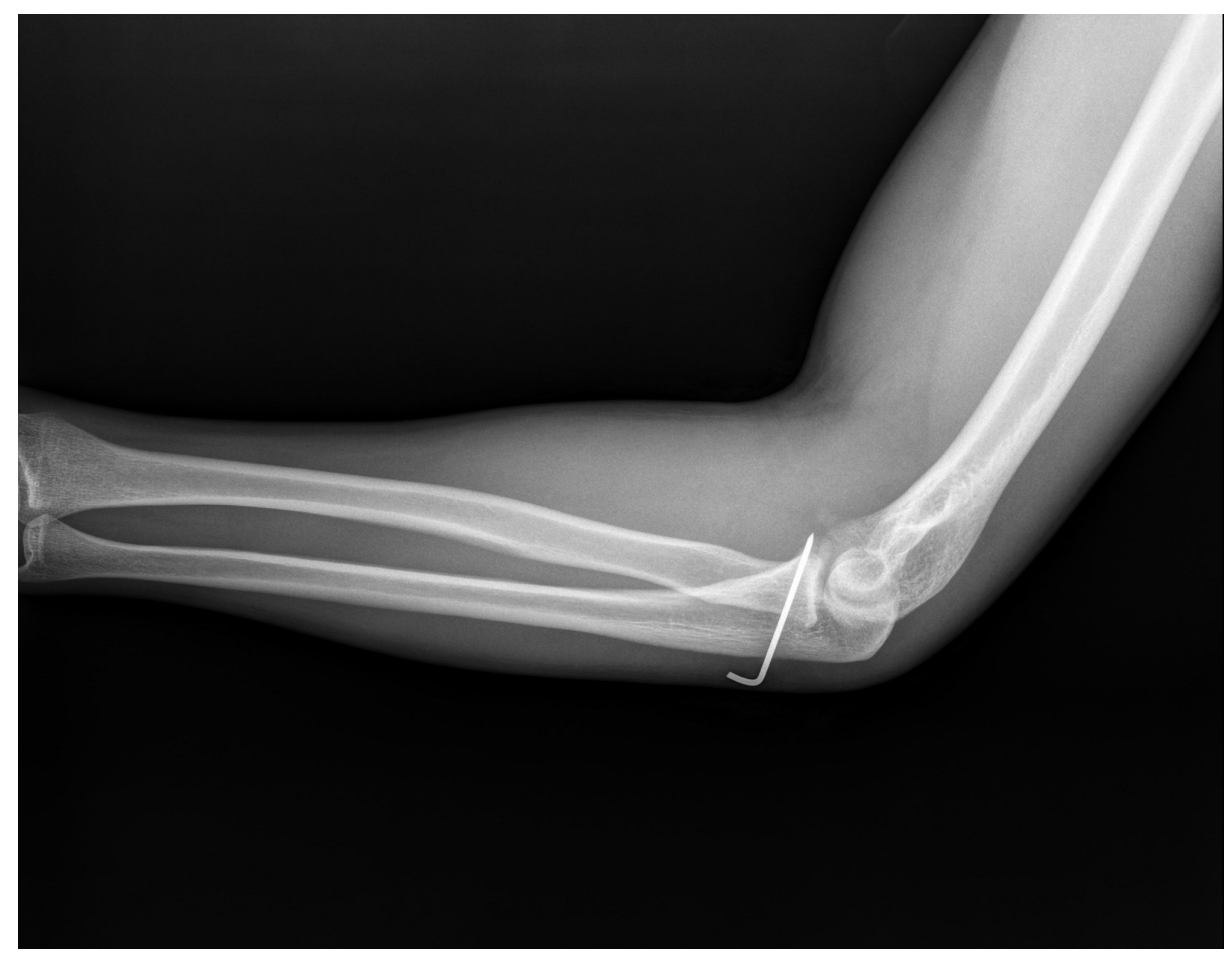

\section{FIGURE 4: Postoperative radiographic images of the patient.}

Radiographic image of the patient shows a K-wire was used to maintain the stability of the reduction of the proximal radioulnar joint.

Postoperatively, a hinged long arm cast brace was applied and the patient was allowed to perform flexionextension movements. Ectopic ossification was observed anterior to the joint at the time of first follow-up. Then, a single dose of 7-Gy radiotherapy was administered to the patient. No progression was detected in ectopic ossification at the subsequent follow-up. The wire and cast brace were removed after four weeks and elbow mobilization was initiated (Figure 5).

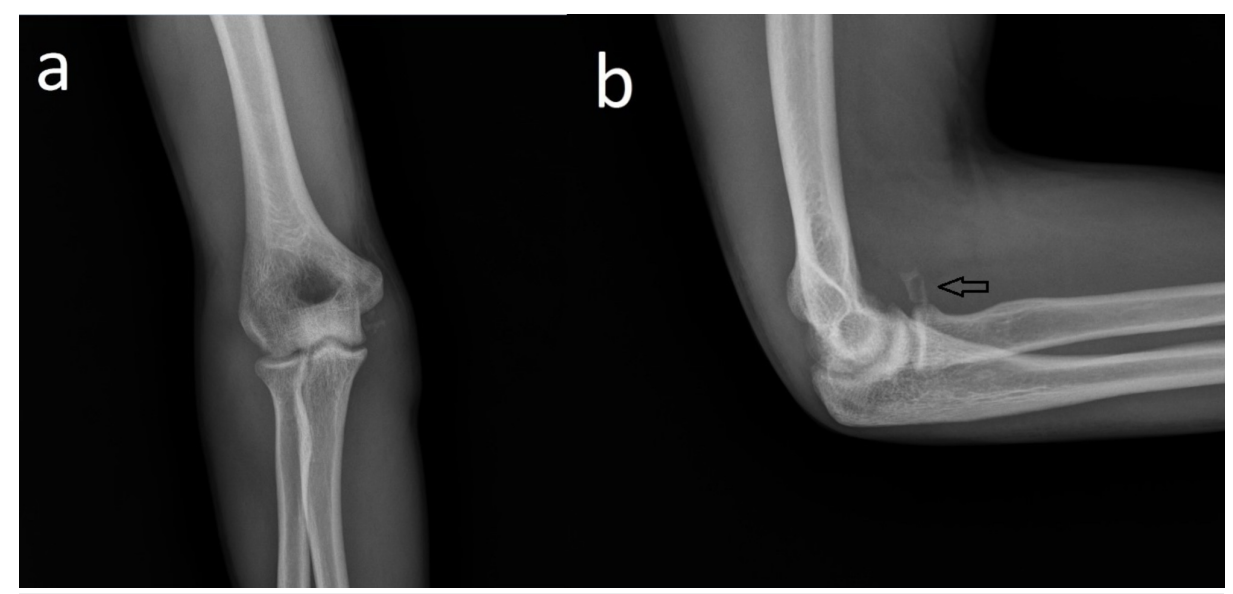

\section{FIGURE 5: Radiographic images at follow-up.}

Radial head in reduced position $(a, b)$. Minimal ectopic ossification developed at the anterior of the joint capsule (arrow).

During the course of subsequent follow-ups, it was observed that the patient had gradually resumed his normal activities. The functional outcome of the patient improved without pain or disability (Figure 6). 


\section{Cureus}

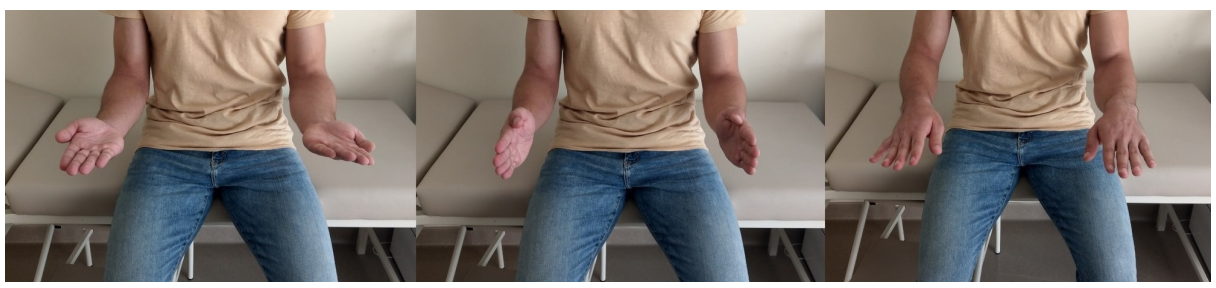

FIGURE 6: Postoperative upper-extremity images.

The appearance of the patient's right elbow range of motion at the end of follow-up.

\section{Discussion}

Traumatic radial head dislocation is usually associated with fractures of the forearm [1,4-8]. Isolated radial head dislocation in adults is rare [1-8]. Only a few cases of truly isolated traumatic anteromedial or anterior radial head dislocation have been reported (Table 1) [1, 4-7].

\begin{tabular}{|l|l|l|l|l|l|}
\hline Study (year) & Sex & $\begin{array}{l}\text { Mean age } \\
\text { (years) }\end{array}$ & $\begin{array}{l}\text { Type of } \\
\text { dislocation }\end{array}$ & $\begin{array}{l}\text { Type of soft tissue } \\
\text { interposition }\end{array}$ & Treatment \\
\hline $\begin{array}{l}\text { Kansay et al. (2018) } \\
\text { [6] }\end{array}$ & Male & 18 & $\begin{array}{l}\text { Anterior } \\
\text { dislocation }\end{array}$ & $\begin{array}{l}\text { Anterior joint } \\
\text { capsule }\end{array}$ & $\begin{array}{l}\text { Open reduction - repair of the annular ligament } \\
\text { - Kirschner wire fixation }\end{array}$ \\
$\begin{array}{l}\text { Climent-Peris et al. } \\
\text { (2016) [4] }\end{array}$ & Female & 14 & $\begin{array}{l}\text { Anteromedial } \\
\text { dislocation }\end{array}$ & Biceps tendon & Open reduction - repair of the annular ligament \\
$\begin{array}{l}\text { Cates et al. (2016) } \\
{[5]}\end{array}$ & Male & 16 & $\begin{array}{l}\text { Anteromedial } \\
\text { dislocation }\end{array}$ & Brachialis tendon & Open reduction \\
$\begin{array}{l}\text { Watanabe et al. } \\
\text { (2005) [1] }\end{array}$ & Male & 24 & $\begin{array}{l}\text { Anterior } \\
\text { dislocation }\end{array}$ & Annular ligament & Open reduction - repair of the annular ligament \\
\hline $\begin{array}{l}\text { Takami et al. (1997) } \\
\text { [7] }\end{array}$ & Male & 20 & $\begin{array}{l}\text { Anterior } \\
\text { dislocation }\end{array}$ & Annular ligament & Open reduction - Kirschner wire fixation \\
\hline
\end{tabular}

TABLE 1: Studies available in the literature on irreducible isolated traumatic anteromedial or anterior radial head dislocation due to soft tissue interposition reported in adult patients.

Closed reduction has been shown to be successful in most isolated radial head dislocation cases [4-6] Inability to perform the reduction procedure due to brachialis tendon interposition is a rare situation, with only one previously published case in the literature [5]. Interposition of the biceps tendon, annular ligament, and anterior capsule have also been described as causes of irreducible anterior radial head dislocation $[1-4,6-7]$.

Radial head dislocations can usually be reduced by simple maneuvers [1, 4-6]. However, surgery may be necessary to reduce radial head dislocations transposed with soft tissue [6]. In very few cases, open reduction has been required [1-7].

Radial head dislocations are caused by a variety of mechanisms [1, 3-7, 9-10]. Injury resulting from a fall in a hyperextended and supination position may cause anterolateral radial head dislocation $[3-4,6,9]$. This situation may be followed by hyperpronation which displaces the head medially, and subsequent flexion of the elbow entraps the tendon around the radial neck $[3-4,6,9]$. This blocks the head in a medial position and prevents closed joint reduction $[3-4,6,9]$. Takami et al. reported a case of a patient with an isolated anterior radial head dislocation after a direct blow to the posterior aspect of a semi-flexed elbow [7]. Salama et al. reported an anterior radial head dislocation after a biceps contraction caused by an electric shock [10]. Sasaki et al. suggest that hyperpronation plays an important role in causing such an injury [3]. In our case, the mechanism of dislocation was considered to be related to extension of the elbow and dorsiflexionhyperpronation of the wrist.

The annular ligament is the primary stabilizer of the proximal radioulnar joint $[1,7]$. Other structures such as the quadrate ligament and interosseous membrane also provide stability to this joint [9]. The annular ligament provides multidirectional stability to the proximal radioulnar joint in patients with gross instability 
of the radial head [9]. Thus, the authors recommend performing annular ligament repair [6]. Radial head dislocation is usually accompanied by damage to the annular ligament. In the presented case, the annular ligament was found to be disrupted and was, therefore, repaired.

Radial head instability can sometimes develop after reduction $[1-7,11]$. Therefore, treatments such as radial head excision, K-wire fixation, and modified Bell-Tawse repair have been proposed [1-7, 11]. In the presented case, after repairing the annular ligament, K-wire fixation was performed for three weeks to create a stable reduction.

Ectopic ossification can often appear after joint dislocation [1]. Accordingly, in our case, an ectopic ossification appeared at the time of follow-up. A single dose of 7-Gy radiotherapy was administered to the patient. No progression in ectopic ossification was detected at subsequent follow-up.

\section{Conclusions}

We presented a rare case of isolated radial head dislocation in an adult patient. The brachialis tendon was wrapped around the radial head, pulling the dislocated radial head anteromedially. We suggest that transposed brachialis tendon or other soft tissues should be taken into consideration in the management of a radial head dislocation if radiographs indicate that the radial head is dislocated anteromedially. Consequently, surgical reduction may be required in such cases.

\section{Additional Information}

\section{Disclosures}

Human subjects: Consent was obtained by all participants in this study. Conflicts of interest: In compliance with the ICMJE uniform disclosure form, all authors declare the following: Payment/services info: All authors have declared that no financial support was received from any organization for the submitted work. Financial relationships: All authors have declared that they have no financial relationships at present or within the previous three years with any organizations that might have an interest in the submitted work. Other relationships: All authors have declared that there are no other relationships or activities that could appear to have influenced the submitted work.

\section{References}

1. Watanabe K, Iwabu S, Hosoya T: Traumatic isolated anterior dislocation of the radial head in an adult: a case report. J Shoulder Elbow Surg. 2005, 14:554-556. 10.1016/j.jse.2004.08.005

2. Yoshihara Y, Shiraishi K, Imamura K: Irreducible anteromedial dislocation of the radial head caused by biceps tendon clinging around the radial neck. J Trauma. 2002, 53:984-986.

3. Sasaki K, Miura H, Iwamoto Y: Unusual anterior radial head dislocation associated with transposed biceps tendon: a case report. J Shoulder Elbow Surg. 2006, 15:15-19. 10.1016/j.jse.2005.08.021

4. Climent-Peris VJ, Sirera-Vercher J, Sanz-Amaro MD: Irreducible anteromedial dislocation of radial head with biceps tendon interposition. Case Rep Orthop. 2016, 2016: 10.1155/2016/5812353

5. Cates RA, Steinmann SP, Adams JE: Irreducible anteromedial radial head dislocation caused by the brachialis tendon: a case report. J Shoulder Elbow Surg. 2016, 25:232-235. 10.1016/j.jse.2016.04.017

6. Kansay R, Gupta S, Soni A, Malhotra A, Garg SK: Isolated anterior dislocation of radial head in an adult with atypical presentation: a case report. Rev Bras Ortop (English Edition). 2018, in press. 10.1016/i.rboe.2018.03.003

7. Takami H, Takahashi S, Ando M: Irreducible isolated dislocation of the radial head . Clin Orthop Relat Res. 1997, 345:168-170.

8. Shelton J, Nixon M: An atypical case of medial radial head dislocation . Ann R Coll Surg Engl. 2016, 98:165167. 10.1308/rcsann.2016.0216

9. Hayami N, Omokawa S, Iida A: Biomechanical study of isolated radial head dislocation . BMC Musculoskelet Disord. 2017, 18:470. 10.1186/s12891-017-1829-

10. Salama R, Wientraub S, Weissman SL: Recurrent dislocation of the head of radius . Clin Orthop. 1977, 125:156-158.

11. Kong KC: Irreducible isolated dislocation of the radial head in a skeletally mature teenager . Arch Orthop Trauma Surg. 1993, 112:304-305 